\title{
Case Assignment Reconstructed Model of Noun Phrases Predicate Arguments in Albanian Language
}

\author{
Msc. Joana Taçi \\ "Eqrem Çabej" University \\ Email: joanabazaiti@yahoo.com
}

\section{Doi:10.5901/jesr.2014.v4n2p314}

\section{Abstract}

This article aims at dealing with Albanian case category and most importantly with the assignment of Nominative, Dative and Accusative case. Syntactically, each noun phrase used in one of the abovementioned case forms within a certain sentence bears also the corresponding subject, direct object and indirect object function. As so within the generative point of view these noun phrases, being assigned these cases and at the same time bearing the above syntactic functions, are targeted as verbs argument (internal or external). It is obvious that case assignment will be treated basically from the generative point of view, explaining that the Generative Linguistics represents a relatively current linguistic theory which from'50s up to now it has been subject to a continuous and long study and restudy process undergoing objections and challenges aiming at its amelioration and its internal and external layer unification. We are quite aware, that this new linguistic theory it has been successfully applied in the linguistic layer of western countries whereas in the Albanian linguistic domain it is in its first steps toward adaptation and introduction. As a result the article I intend to present will focus on the assignment of Nom, Acc and Dat. case and the case assignment model (inherent or structural) they belong to. Let us highlight here that the early generative analysis concerning case assignment, proposed two such models inherent (dative case) and structural (nominative and accusative). But within the contemporary studies we have come across that such a division does not exist anymore (concerning these three cases) because all the above cases assigned to noun phrases verb arguments belong to structural case assignment model.

Keywords: Noun phrase, internal argument, external argument, inherent case, structural case, thematic assignment.

The internal structure that is stored in every individual mental lexicon is made up of a complete wordlist and of a detailed information concerning each.

\section{Projection Principle ${ }^{1}$}

The lexicon properties are projected in the sentence structure/syntax.

The sentence structure depends especially on the relations established between the predicate and its noun phrases arguments. The noun phrases presence and number represents what is known as predicate valence. This notion, used for the first time by the French linguist Tesniere ${ }^{2}$, has been adopted into linguistics from the science of chemistry. On the other hand, the selection of arguments and their number depends on the semantic properties of the predicate itself. In other words, such a argument-predicate dependence is highly influenced by the predicate necessity to fulfill its valence. In this context, the predicate category is classified ${ }^{3}$ as follows:

Predicate of zero valence (present in inflectional languages as Albanian): Bubullin, Vetetin, etc. In general this predicate subdivision of Albanian language refers to atmospheric phenomena.

One valence predicate: eci, shkoj, arrive, depart etc. The predicates of this subdivision ask for the presence of one argument in order to fulfill their semantic properties.

Two valence predicate: shoh, dua, want, see etc. These predicates ask for the presence of two arguments.

Three valence predicate: jap, dhuroj, give, donate, etc. this predicate subdivision known as double object

\footnotetext{
1 Projection Principle of Chomsky (1982;29) according to Rami Memushaj "Gjuhësia Gjenerativeve”, 2008, p 140

2 Dhima Th. "Mbi klasifkimin e foljeve sipas valences", Paper on the International Congress of Albanian Language, Literature and Culture, 2002

${ }^{3}$ Dhima Th. "Mbi klasifkimin e foljeve sipas valences", Paper on the International Congress of Albanian Language, Literature and Culture, 2002
} 
predicate in English language ask for the presence of three arguments.

Driven by the above subdivisions. concerning the argument structure of predicates, L. Heageman ${ }^{4}$ explains such a phenomena in the following metaphor: "The predicates are like the script of a play. In the script a number of roles are defined and will have to be assigned to actors. The arguments of the predicate are like the roles defined by the script of the play. For an adequate performance of the play each role must be assigned to an actor. It will not do either to miss out on a part in the play or to have actors on the stage who have no part to play. A script of a play defines not only the number of parts to be assigned, hence the number of actors involved, it also specifies which roles these actors have to play"

In the second part of this metaphor are specified the relationships established between the verb and its respective arguments. The more specific relationships held between the verb and its arguments, referred to in terms of Theta Theory, are those of agent, theme/patient or receiver.

Example:
1. Djali
i dhuroi nje kukull
motres
The boy donated a doll
Agent theme
to his sister
receiver

The predicate has been widely accepted as the assigner of the above theta roles, but the following examples hold the contrary.

Example

1.a Joni theu xhamin

John broke the vase

1.b Joni theu krahun

John broke his arm.

Both the above examples have the same syntactic structure. The difference lays on the subject argument semantic role which in 1.a example its thematic role is that of the agent while in 1.b example the subject NP "Joni/John" represents the thematic role of the experiences as Joni/John is the one who underwent the "breaking" event.

This difference on the subject thematic role is closely related to the semantic information of the second argument NP "xhamin/vase" in the firs example and "krahun/arm" in the second one.

In this context it is believed that the subject thematic role is assigned compositionally, so it is determined by the semantic relation of the verb and its argument ("xhamin/krahun") which is directly theta marked by the verb. This second $\mathrm{NP}$, which is directly theta marked, is referred to as internal argument being assigned internal theta role.

Whereas, the NP realized in subject position and which is indirectly theta marked is referred to as external argument being assigned external theta role.

These internal and external predicate arguments, subject or object, in order to be visible in the sentence structure (related to the Principle of Visibility ${ }^{5}$ ) should be assigned Nominative, Accusative and Dative case. The distribution of these case forms is closely related to one of the most important modules of generative linguistics, that of Case Theory.

The generative perception of case theory it is analyzed within to theoretical developing periods ${ }^{6}$.

- The first period - up to the end of '80. The generative perception of case assignment within this period it is not yet been divided from the traditional analyses, as case assignment is determined by the syntactic governing relations.

- The second period - after ' 90 . The generative perception of case divided by the traditional analyses is now embedded within the Minimalist Program, according to which the NP enters the sentence structure equipped with case properties which have to be represented in the structural tree.

\section{Arguments Case Assingment Up to ' 80}

Every simple sentence identifies a phrase bearing a more complicated structure than that of a VP ${ }^{7}$ projection. This proposal is strongly supported by the existence of the auxiliary verbs which have no lexical properties of their own as they are always followed by a participle (the participle bears the lexical properties)

Example.

\footnotetext{
${ }^{44}$ Heageman L. "Introduction to government and binding theory, Cambridge University press, 1991

${ }^{5}$ Memushaj R. "Gjuhësia Gjenerativeve", 2008

${ }^{6}$ Buxheli L. "Modelet e caktimit rasor në gjuhën e sotme shqipe", 2007,

${ }^{7}$ Dhima Th. "Disa veçori të frazës shqipe në këndvështrimin e gjuhësisë së sotme", 2007
} 
1.a Djali ka lexuar librin.

The boy has read the book.

Secondly, the obligatory presence of the subject, even in cases when it is not necessary to the lexical subcategorization frame of the predicate supports the complicated structure of the sentence. This is the case of English language expletives.

Thirdly, both the lexical verbs and the auxiliary ones offer important mood, tense and person information which in Albanian language agree with the sentence subject. These mood, tense and person properties, referred as inflection, determine the sentence structure which is considered as an inflection projection InfIP.

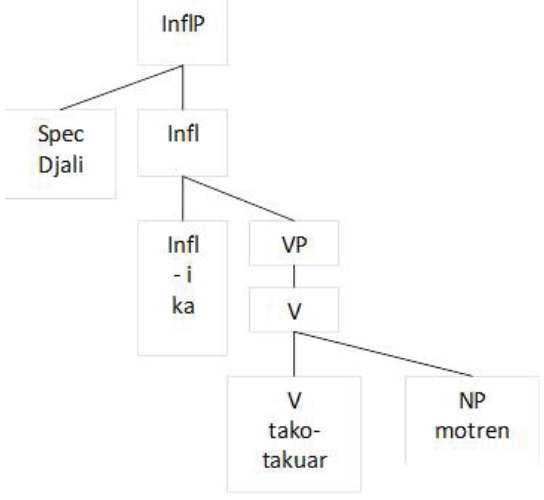

The subject NP "djali" will be generated under the specifier node of the VP projection. This is the position under which this subject NP takes the semantic role of the agent. Being equipped with the agent semantic role the subject NP moves toward a higher specifier position that of the InflP. This movement is triggered by the necessity of the Infl head to license its inflectional properties and as so to assign nominative case to the subject NP.

According to the Internal Subject Hypothesis ${ }^{8}$ it has been widely accepted (for every synthetic or analytic language) that the external NP argument in order to license its semantic properties is firstly generated under the specifier node of the VP projection and afterword it moves toward the specifier node of the InfIP where the inflectional properties are licensed and nominative case is assigned.

Furthermore, considering the fact that case assignment, accepted as a fundamental condition its fulfillment being highly determined by the arguments visibility, demands the assignment of the accusative case as well.

The internal argument, syntactically identified as direct object, is not assigned accusative case by the same inflectional head (as we have accepted with the nominative case assignment) as it is not fulfilled the Governing Condition.

According to the above sentence $X^{\prime}$ scheme, the internal NP argument is generated under the NP projection sister to the V0 head of the VP. This VP projection serves as a barrier for the object NP to be governed by the Infl0. As so it is assumed that the accusative case by the verb $\left(\mathrm{V}^{0}\right)$ only if it is generated in the [NP; VP] configuration, so under to sister branching NP projection of $\mathrm{V}^{0}$.

In addition Albanian language as well makes use of double object constructions such as:

Example

1.a Djali i dhuroi nje kukull motres

The boy donated a doll to his sister

The second internal object syntactically representing the indirect object it has been assigned the semantic role of the receiver. Following the same analysis as we have done with the accusative case assignment we are opt to accept that the verb "dhuroj/donate" does not only theta mark this second NP but it assigns it the dative case.

As so the accusative and dative cases are assigned internal the VP maximal projection.

${ }^{8}$ McClosey J., Subjecthood and Subject Position 


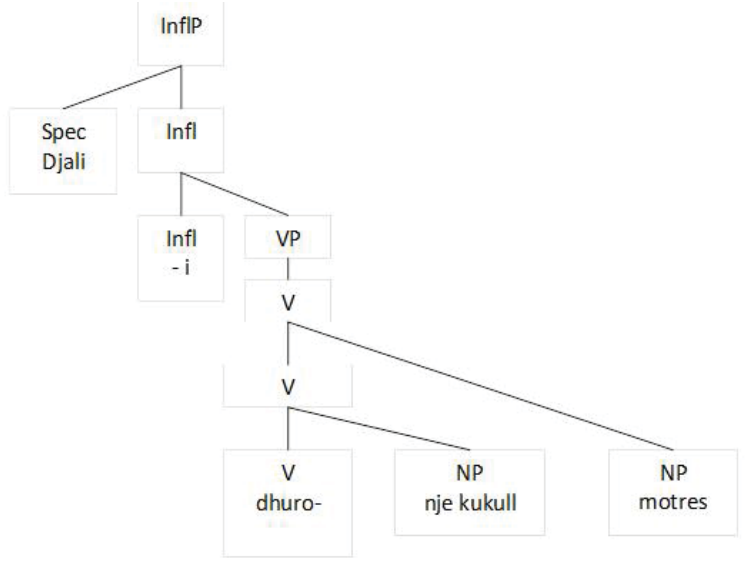

The above case assignment models have been challenged after 1990s as the case assignment phenomenon has underwent structural transformational processes.

\section{Case Assignment Under The Specifier-Head Configuration}

Chomsky by the second developmental period of generative analysis concerning case assignment introduced a new restructuring treatment of the Nominative, Accusative and Dative case assignment to the respective NP arguments. His approach highlights the importance of the agreement category as the only one responsible in licensing case properties. Such proposal I based mostly on the fact that both case and agreement are considered as the main mechanisms in expressing grammatical relations. In addition Chomsky proposes two layers of agreement: the one concerning nominative case assignment to the external argument and the second one concerning the assignment of accusative and dative case to the respective internal arguments.

The first layer is represented by the subject agreement phrase AgrSP whereas the second one is represented by the direct object agreement phrase AgrOP and the indirect object agreement phrase AgrlnOP.

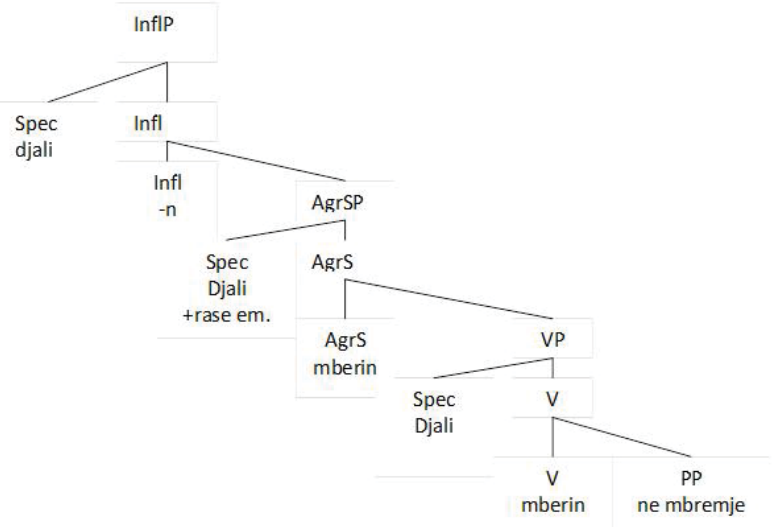

According to the above X' projection we summarize that the subject NP "Djali" being generated under the specifier node of VP (where is theta marked) moves toward the specifier node of the AgrSP to be license case properties and finally it moves toward specifier node of InfIP (it precedes the verb + inflection composition realized under Infl0.)

Comparing both models (up to ' 80 and after ' 90 ) of nominative case assignment we conclude that what brings them together is the assignment of nominative case within the specifier-head configuration.

In this context that as both external and internal NP are considered as verb arguments, the case assignment under specifier-head configuration will be distributed to the assignment of accusative and dative as well. 
Analogically, it has been proposed the generation of AgrOP in between the InfIP and VP projections. The direct object NP basically generated within the [NP;VP] structure it is moved toward the specifier node of AgrOP.

Example

1.a Djali mori lapsin

The boy took the pen.

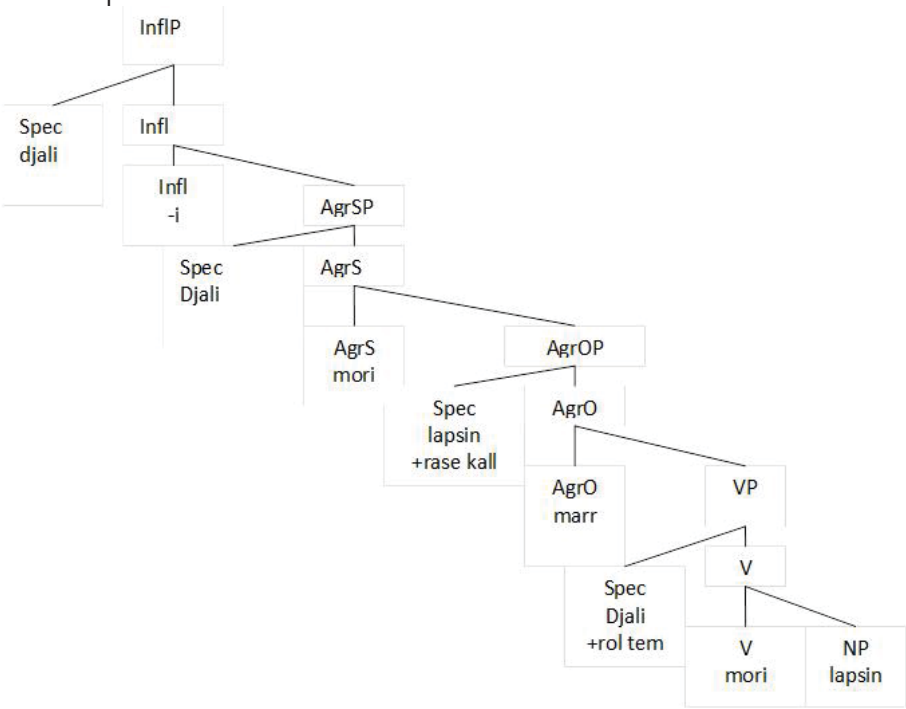

Such $X^{\prime}$ projection is problematic as the internal NP argument which moved form the [NP;VP] position toward the SpecAgrOP skipping the SpecVP position is unacceptable due to Locality Condition ${ }^{9}$. In this context Chomsky proposed the Split VP Hypothesis which divides the VP lexical projection in two others such projection the higher VP and the lower one VP. The functional projection of AgrOP is generated in between VP and VP.

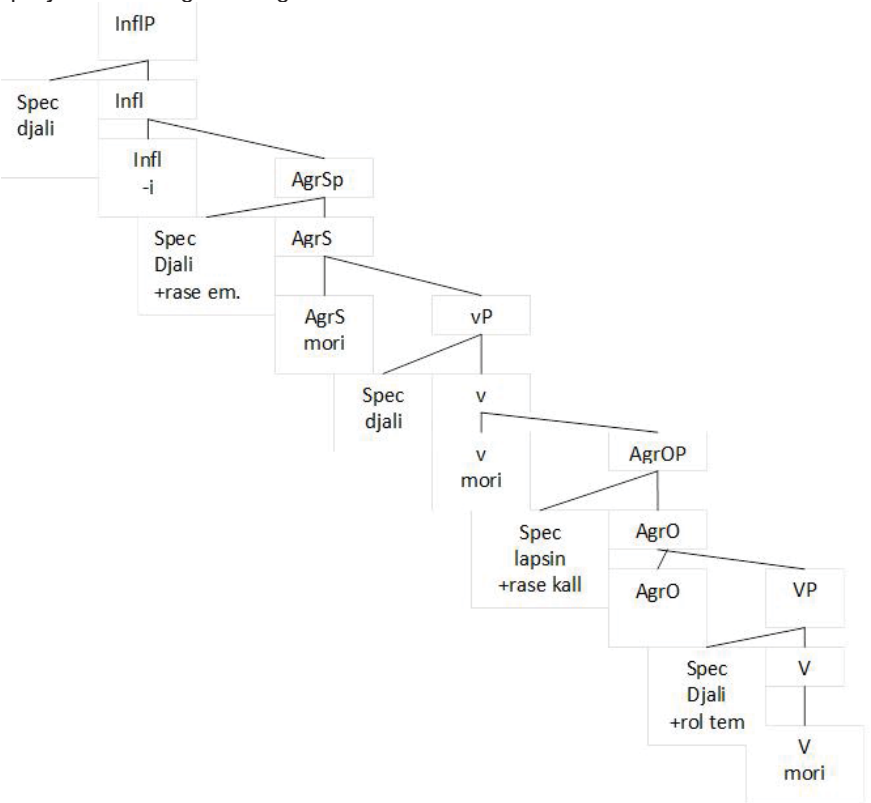

${ }^{9}$ Abney S. The English noun phrase in its sentential aspect, 1987 
The above direct object projection and realization, even though it is considered appropriate, it is doubtful as it skips what was previously accepted as the basic position for the direct object NP to be generated, that of [NP;VP].

Chomsky goes further by proposing the same case assignment model for the double object constructions.

\section{Example}

1.a Djali i dhuroi nje kukull motres

The boy donated a doll to his sister

Considering these double object construction of Albanian language it is proposed that the verb together with its internal objects will be treated as a simple sentence. So the internal argument indirect object syntactically and semantically would be characterized as the sentence subject generated under the specVP node. Whereas the internal argument direct object would be positioned in the [NP;VP] structure.

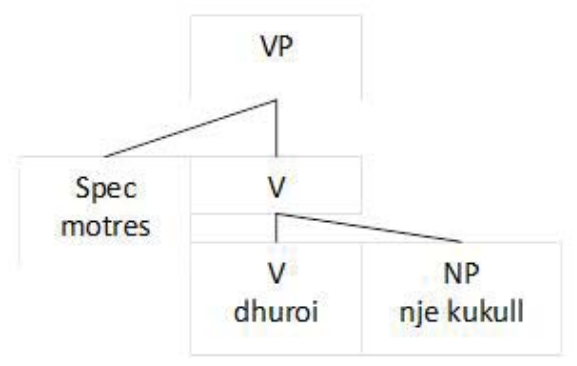

The above VP projection will be firstly merged to the AgrOP projection (in specAgrOP should be realized the direct object $\mathrm{NP}$ ) and later on this AgrOP will be merged with the AgrlnOP (in specAgrlnOP will be realized the indirectobject NP.)

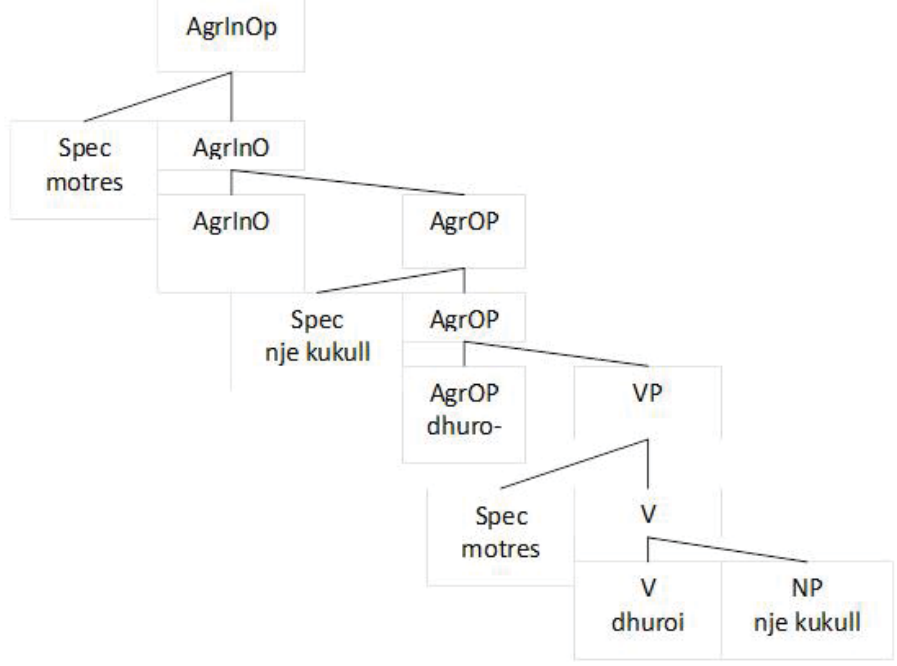

This AgrlnOP projection will be merged to the vP projection. In the v0 head of this projection will be realized a null verbal category bearing a causative meaning.

In the specifier position of the VP will be realized the NP external argument. This NP subject is realized under the SpecvP node in order to be assigned the agent theta role.

Being equipped with the agent theta role this subject NP moves toward the specifier position of the AgrSP. 


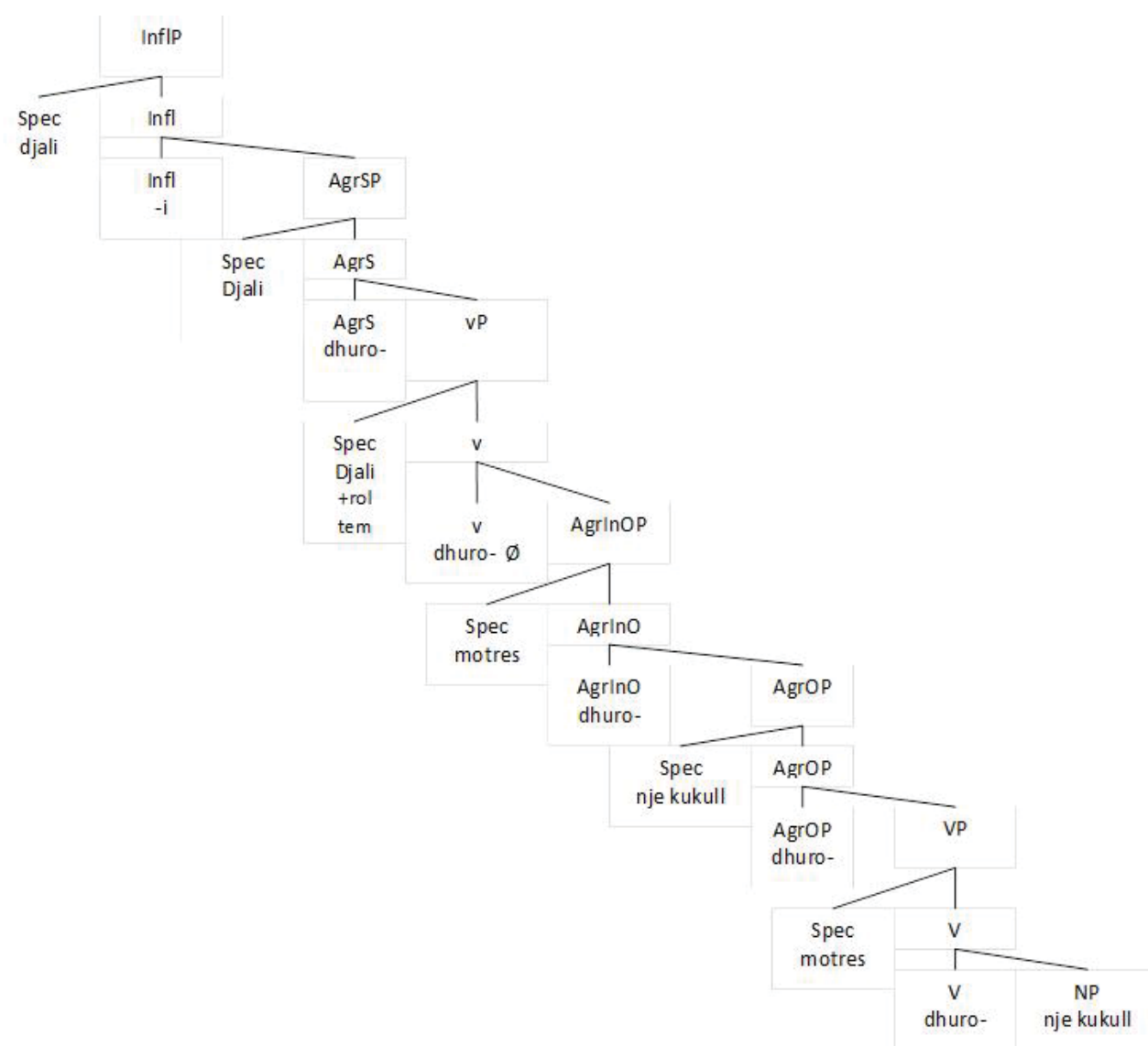

Taking into close consideration the last model of nominative, accusative and dative case assignment it is assumed that, as these cases are assigned only to the verb's arguments, their case assignment position is unified. So the assignment of the above cases it is realized under specifier-head configuration.

The NP arguments (external or internal) in order to be case marked must be realized under the respective specifier positions (SpecAgrSP; SpecAgrOP; SpecAgrlnOP). Such a conclusion supports the fact that the assignment of Nominative Accusative and Dative is a mere representation of structural case assignment model.

\section{References}

Memushaj R. "Gjuhësia Gjenerativeve", 2008

Dhima Th. "Mbi klasifkimin e foljeve sipas valences", Kumtese në Seminarin Nderkombetar per gjuhen, letersine dhe kulturen shqiptare, Prishtine 2002

Heageman L. "Introduction to government and binding theory, Cambridge University press,1991

Memushaj R. "Gjuhësia Gjenerativeve", 2008, fq 175

Buxheli L. "Modelet e caktimit razor në gjuhën e sotme shqipe", 2007, fq 51

Dhima Th. "Disa veçori të frazës shqipe në këndvështrimin e gjuhësisë së sotme", 2007

McClosey J., Subjecthood and Subject Position

Abney S. The English noun phrase in its sentential aspect, 1987 
